\title{
Context and communicative success
}

\section{Joey Pollock}

Email: joeykpollock@googlemail.com

ConceptLab, University of Oslo, Oslo, Norway

\begin{abstract}
Traditional accounts of the conditions on communicative success are invariantist. For example, some authors claim that, for communication to succeed, a hearer must always grasp the very content that the speaker expressed with her utterance; others claim that success is always proportional to the degree to which the hearer understands this content. In this paper, I argue that these invariantist approaches cannot offer a comprehensive account of communicative success. When we attempt to communicate, it is usually with the intention to secure some perlocutionary effect beyond the communicative exchange itself (for example, to get our interlocutor to pass the salt, or to convince her to form a particular belief). I argue that, relative to these intentions, it may not matter whether a hearer perfectly understands the speaker; it may not even matter if the hearer's understanding is quite poor overall. In place of invariantist conditions (or perhaps, in addition), I propose an approach that is context-dependent in the following sense: holding fixed the content expressed by the speaker, differences in features of the broad context of the speech exchange can determine differences in the standards for communicative success. On this approach, success requires that the hearer understand the content expressed by the speaker in ways that are relevant to the speaker's perlocutionary intentions.
\end{abstract}

Keywords: Communication; context; perlocutionary intention; understanding; mental content

\section{Introduction}

When a speaker produces an utterance, under what conditions does she succeed in communicating with her audience? ${ }^{1}$ There are different answers to this question in the literature. For example, some authors adopt a 'shared content' approach to communication. Shared content approaches claim that, for communication to succeed, the hearer must grasp the very content that the speaker expressed with her utterance. An alternative approach is to claim that success requires, not shared content, but merely some suitable degree of similarity between the content grasped by the hearer and that expressed by the speaker. Whilst these approaches offer different pictures of communicative success, they are each committed to a kind of invariantism: they claim that the standards for communicative success remain

\footnotetext{
${ }^{1}$ I understand 'utterance' broadly here, to refer to the signal in a communicative exchange; I intend this to include signals that are written, signed, spoken aloud, etc. Similarly, I use 'speaker' and 'hearer' to refer to the sender and receiver of this signal, respectively. (cf. Grice 1957: 380)
} 
constant across different speech exchanges. In this paper, my aim is to demonstrate that there are instances of successful communication that these invariantist approaches cannot accommodate. What is missing from invariantism is an appreciation of the ways in which features of the context of the communicative exchange can place varying demands on interlocutors. I will argue that consideration of the role of such features in communication motivates a context-dependent understanding of communicative success (either alongside, or instead of, invariantist conditions). It is common to appeal to context in order to explain various elements of a communicative event. For example, relevance theorists have argued that context plays an important role in the processes by which a hearer recovers content from the speech exchange; context is also thought to play some role in determining what is said by the speaker for some kinds of expression. My approach in this paper highlights a different kind of function that certain features of context (broadly construed) can play in a communicative exchange: that of determining the standards for communicative success.

The paper proceeds as follows. In Section 2, I offer some preliminary remarks concerning communicative exchanges and content individuation. In Section 3, I explain several invariantist conditions on successful communication. In Section 4, I offer a series of examples designed to motivate my context-dependent account over (pure) invariantism. In Section 5, I consider further support for the intuitive verdicts on these examples.

\section{Communication and content individuation}

A communicative exchange is an event with the following structure: the event begins with some contentful mental state of the speaker; this mental state (partly) causes the production of an utterance; the utterance is received by a hearer; and this hearer is thereby caused to enter into a contentful mental state of her own. ${ }^{2}$ Beyond this rather simple description of the event, there are many questions that arise concerning the finer details. For example, the above description involves two mental states of the speaker and hearer, respectively; how is the content of these states individuated? What relation does this mental content stand in to the content of the utterance that the speaker produces? How is it exactly that the hearer recovers content from the exchange? What we say about the nature of mental and utterance content can make a significant difference to an explanation of communication and communicative success. Thus, before examining various candidate conditions on communicative success, I will first say a bit about content individuation.

\footnotetext{
${ }^{2}$ Here I am roughly following Pagin (2008). Pagin offers a more detailed, and more general, characterisation of the structure of a communicative event; however, many of these details are not important for my purposes.
} 
It will be useful to make a distinction between sociolectical and idiolectical theories of content individuation (for both mental content and utterance content ${ }^{3}$ ). Sociolectical theories claim that subjects can very often think thoughts, and produce utterances, that contain or express concepts that are typeidentical to those possessed by others in the same language community. That is (ambiguity and polysemy aside), speakers in a language community who utter the same word-forms will often thereby express the same concepts. Many externalist approaches to meaning and thought content are sociolectical (e.g., Burge 1979, Putnam 1975, Fodor 1994, Millikan 1984). Externalists claim that content is individuated, in part, by factors external to the subject, such as her social and/or physical environment. In contrast, idiolectical theories claim that, rather than sharing a public language, subjects each speak and think in their own idiosyncratic idiolects. On idiolectical theories, two subjects will rarely express the same concepts with utterances of the same word-forms. This approach is most often internalist; internalists claim that content is determined solely by factors internal to the individual. An example would be a radical holism according to which concepts are individuated by their relationships to all other concepts in a subject's conceptual web (e.g., Rapaport 2003).

One central difference between the approaches is how they treat the relationship between content and (a certain kind of) conceptual and linguistic understanding. A sociolectical theory will allow that content and understanding can come apart: a subject can grasp a concept whilst having very little understanding of its content. To take Burge's (1979) famous example: a patient, Alf, is said to possess the communal concept ARTHRITIS even though he is seriously confused about the concept's correct application. Alf believes that he has arthritis (a disease of the joints only) in his thigh; and this, Burge claims, is a conceptual error. Subjects like Alf, who are conceptually confused, can nonetheless share concepts with others in their community because the conditions on conceptual grasp are relatively undemanding. Burge suggests that, to be attributed a communal concept, a subject must possess a general competence with respect to her language as a whole (or relevant parts of it) and be disposed to defer to experts with respect to the correct application of the concept (1979: 114). Other than this, however, subjects can be quite seriously mistaken - or just agnostic - as to the application conditions of a concept and still possess it. On sociolectical theories, once we have settled the question of whether an individual grasps a particular concept, we have not thereby settled the question of whether (or to what extent) she understands this concept. As I will explain below, this means that one might want to require both content recovery and understanding in one's account of communicative success. Whereas a sociolectical theory will allow that understanding can float largely free of content, an idiolectical theory will claim that content closely tracks our understanding of it: we cannot be very wrong about the content of the concepts we possess. For example, if I am disposed to assent to 'All dogs are molluscs', an idiolectical

\footnotetext{
${ }^{3}$ These theories of content individuation are also relevant to the determination of the linguistic meaning of words and sentences, where linguistic meaning can be thought of as distinct from utterance content.
} 
theory might claim that I don't have incorrect understanding of a public DOG concept; rather, I have correct understanding of my own idiosyncratic concept, DOG*. On this approach, content and understanding are just two sides of the same coin. For an idiolectical theory, then, grasping a content, and understanding that content, might come to more or less the same thing.

The structure of the account of communicative success that I will argue for in this paper is designed to be compatible with many different theories of the individuation and structure of content, including both sociolectical and idiolectical theories; however, the way that the account is stated will vary significantly depending on one's preferred approach to these issues. For ease of exposition, I will make a few assumptions. Firstly, I will assume the sociolectical framework for both thought content and utterance content when presenting my argument. Secondly, I will restrict my focus to exchanges in which an utterance's content does not diverge from the thought content it is used to express. ${ }^{4}$ Thirdly, I will assume that an utterance can express, at most, one content - that is, I assume what Cappelen and Lepore (2005) call 'speech act monism'. In the next section, I explain in more detail the invariantist conditions on communicative success that I will critique.

\section{Communicative success and invariantism}

Invariantist theories of communicative success claim that the standards for success do not vary with the context of the speech exchange - where 'context' here, should be understood in the broad sense, to include things like the interlocutors' background knowledge ${ }^{5}$ as well as physical features of the environment of the speech exchange. For the invariantist, this context might play some role in, for example, the hearer's recovery of content; but it plays no role in determining the standards for communicative success in the following sense: if a speaker expresses the very same thought content, on two different occasions, the standards for success will remain constant across both exchanges. In contrast, I will understand a context-dependent approach as one which claims that, holding fixed the content expressed by the speaker, differences in features of the broad context of the speech exchange can result in differences in the standards for success. ${ }^{6}$ I don't claim that this is the only way to understand what context-dependence amounts to with regards to communicative success; rather, this understanding marks an interesting division between different kinds of approach.

\footnotetext{
${ }^{4}$ Utterance content need not always match the content of the thought expressed - subjects may sometimes misspeak, for example. Cases in which the two diverge cause complications. I think that grasp of utterance content itself is not required for communicative success. In Pollock (2015), I argue that, on sociolectical theories, what must be grasped by a hearer is not utterance content, nor even thought content, but a speaker's understanding of the thought content she expresses (Thanks also to Andrew Peet for helpful discussion of this issue). I ignore this complication in what follows.

${ }^{5}$ We could think of this as common ground (Stalnaker 2002, Clark 1996). However, I don't think it is necessary that speaker and hearer share the relevant beliefs.

${ }^{6}$ Note that the account is not contextualism about the term 'communicative success'.
} 
There is a range of invariantist conditions on communicative success that you might endorse. In the next section, I will set out two prominent kinds of necessary condition: conditions on content, and conditions on understanding. ${ }^{7}$

\subsection{Conditions on content}

When setting out the structure of a communicative event, I said that the exchange includes two contentful mental states of the speaker and hearer, respectively. One kind of condition on communicative success claims that communication requires that some special semantic relationship hold between these mental states. As mentioned above, there are different options for what this relationship must be. The 'same content' approach claims that the content recovered by the hearer must be type-identical to the thought content expressed by the speaker. This is a relatively popular approach in the literature. It is most common when focus is restricted to testimonial knowledge acquisition (E.g., Burge 1993, Fricker 2006, and Goldberg 2007). The approach is also somewhat popular for communication in general; although it is more controversial whether all kinds of communication require shared content. Goldberg (2007), for example, allows that non-testimonial communication might not be so demanding. However, there are those who think that sharing content is central to understanding even non-testimonial communicative success. Cappelen and Lepore (2007: 115), for example, write that "Content sharing [...] is the very foundation of communication." (another example is Newman 2005). If you think that the shared content approach is too demanding, there are various similarity-based alternatives in the literature. For example, one could say that communication succeeds only if the hearer grasps a content that is highly similar to the thought content expressed by the speaker; or that communication succeeds to the degree that the content grasped by the hearer is similar to the content expressed by the speaker. One example of a defender of content similarity is Bezuidenhout (1997) (other examples are Pollock 2015, Jorgensen 2009, Rapaport 2003, Carston 2001). She writes,

We need recognize only speaker-relative utterance content and listener-relative utterance content and a relation of similarity holding between these two contents (where the speakerrelative utterance content is identical to the content of the thought the speaker expresses and the listener-relative utterance content is identical to the content of the thought the listener comes to entertain). (Bezuidenhout 1997: 212)

\footnotetext{
${ }^{7}$ These aren't the only conditions you might include. For example, perhaps the hearer must recover whatever attitude the speaker takes towards the content she expresses, as well as things like the illocutionary force of the utterance.
} 
These various content conditions on success are all invariantist. For example, shared content approaches claim that a hearer must always grasp the very content that the speaker expressed; graded theories claim that success is always proportional to the degree of similarity that holds between the contents expressed by the speaker and grasped by the hearer. It might be that different kinds of communication, or different types of utterance, involve different kinds of condition on communicative success; however, to claim this is not to claim that the standards for success vary with context.

\subsection{Conditions on understanding}

In addition to these content conditions, it seems plausible that successful communication requires some kind of linguistic or conceptual understanding on the part of the hearer. There are many theories in the literature concerning what linguistic understanding consists in. ${ }^{8}$ Only some varieties of understanding would be sensible candidates for additional conditions on communicative success. For example, according to one approach, an act of linguistic understanding is just the means by which content is recovered from the speech exchange. Goldberg (2007), for example, proposes a notion of understanding that characterises it as the process by which a hearer maps the speaker's utterance onto an item of mental content in her own cognitive economy. On this approach, to achieve a state of correct understanding just is to have grasped the content that the speaker expressed. ${ }^{9}$ Following Goldberg, I will call this kind of understanding 'comprehension' to distinguish it from other varieties of linguistic understanding. ${ }^{10}$ If you hold this kind of theory (and you think there is no other kind of understanding) then you might have no need for both a condition on content and a condition on understanding in your account of communicative success.

When might one want a separate understanding requirement? Recall that, in Sect. 2, I explained that sociolectical theories of content entail that subjects can grasp contents that they do not understand. Comprehension, as described above, is the kind of understanding involved in grasping, or recovering, a particular content from a speech exchange. As already emphasised, this still leaves open whether (or to what extent) the hearer understands the content that she has recovered, in some further sense of the

\footnotetext{
${ }^{8}$ Longworth (2010) examines several options.

${ }^{9}$ This approach could be framed as a traditional propositional theory of linguistic understanding, according to which understanding an utterance, $u$, amounts to knowing that $u$ means that $p$, where $p$ is some correct specification of $u$ 's content (e.g., Heck 1995, Evans 1982, Dummett 1987); however, I think it is also compatible with weaker theories that do not treat understanding in terms of propositional knowledge about what was said (e.g., Longworth 2018).

${ }^{10}$ Goldberg uses the phrase 'reliable comprehension'; this is because he is interested in how hearers can acquire testimonial knowledge. As my focus here is not testimony, the reliability dimension of Goldberg's account is not important for present purposes.
} 
term. This latter kind of understanding, I will call 'inferential' understanding. ${ }^{11}$ On this approach, understanding utterance or thought content is a matter of grasping the inferential relations that hold between this content and the rest of your beliefs. You understand the content of an utterance or thought correctly to the degree that you grasp the inferences that it is correct to draw from it. Importantly, inferential understanding is multidimensional: because contents stand in a great many inferential relations to other contents, there are different ways in which you can understand the same content that fall short of a full, correct, understanding. You could, for example, understand the content in a way that is just plain wrong (e.g., if you are disposed to infer from 'Some dogs bark' to 'Some molluscs bark'). Often, however, what happens is that we understand contents partially. For example, you might be disposed to infer from 'Stanley is an octopus' to 'Stanley lives in the sea'; but perhaps not from 'Stanley is an octopus' to 'Stanley has 3 hearts'. Something like this notion of understanding must be in play in sociolectical theories in order to explain the sense, highlighted above, in which a subject can misunderstand the content of her own thoughts and the utterances of others, despite succeeding in grasping these contents. Later, I will try to convince you that this notion of understanding is also integral to an account of communicative success.

An inferential understanding requirement can be fleshed out in different ways, which more or less mirror the content conditions introduced above: success might require that a hearer fully understand the content that she recovers from the exchange, or that she understand quite well; or perhaps she succeeds to the degree that she understands the content recovered. Like the content conditions, these understanding requirements are invariantist and for the same reasons. It might be that no one of the above conditions (on content and on understanding) alone would be sufficient for communicative success. You can hold many of them together if you like. For example, you could claim that the hearer must grasp (comprehend) the right content and also achieve full (inferential) understanding of this content. This is a pretty demanding approach. We could strengthen it still further: perhaps the hearer must not only grasp the right content but know that she has done so and know that her (inferential) understanding is correct. I am inclined to think that such a requirement is too strong - successful communication can be, and often is, lucky (cf. Davidson 1986); ${ }^{12}$ however, the account that I go on to present is compatible with these strengthened requirements on communicative success.

So, to summarise where we've got to so far: A communicative attempt is an event in which a speaker produces an utterance that expresses a thought content; this utterance is received by a hearer who, as a result, enters into her own contentful mental state. For ease of exposition, I'm assuming that some

\footnotetext{
${ }^{11}$ Inferential understanding should not to be confused with the inferential model of communication embraced by relevance theorists. The latter is a view about the role of inference in arriving at an interpretation of the speaker's utterance (Sperber and Wilson 1986, Bezuidenhout 1998).

${ }^{12}$ Pagin (2008) discusses several knowledge requirements on communicative success.
} 
sociolectical theory is true of both thought and utterance content; I am restricting my focus to cases in which these two kinds of content do not diverge; and I'm assuming that an utterance expresses, at most, one content. I've presented some invariantist conditions on communicative success; the important ones are conditions on content and conditions on inferential understanding. On sociolectical theories, when a hearer observes the speaker's utterance, she both grasps a content, and (inferentially) understands this content in a particular way. I will now argue that the invariantist conditions - no matter their combination - cannot offer a plausible (or, at least, a comprehensive) picture of communicative success.

\section{$4 \quad$ Against invariantism}

When we communicate, we are often trying to get our audience to do something - either for us, or with us. For example, to pass the salt, to lift one end of a piano, to form a particular belief, etc. I suspect that, on a suitably broad understanding of what it is to get people to do things, this is the only aim of communication. However, I will not argue for this claim here. Instead, my aim in this paper is somewhat modest: I claim that there is a kind of communication, the aim of which is to get people to do things; and the standards for success, for this kind of communication, are context-dependent. As such, I do not claim that invariantist conditions are never relevant to communicative success. There may be some cases, or kinds, of communication for which all success requires is that you grasp the right content, for example - if so, we should be pluralists about communicative success. My thesis here is that, when we consider the sorts of aims and intentions that a speaker can have, we will find that invariantist accounts cannot tell the whole story.

What features of context affect the standards for communicative success? In what follows, I will focus on what Austin (1962) calls the 'perlocutionary' intentions of the speaker. Perlocutionary intentions are intentions to produce perlocutionary effects. These are effects that utterances can have on the hearer which may fail to obtain even when 'uptake' is secured. ${ }^{13}$ Examples of perlocutionary effects include things like persuading, surprising, and amusing. Austin contrasts perlocutionary intentions and effects with 'illocutionary' intentions and effects. Illocutionary effects are those which are guaranteed so long as uptake is secured (and perhaps even without uptake). ${ }^{14}$ Paradigmatic examples are things like warning, promising, and requesting.

Illocutionary intentions are important for understanding what it is that the speaker intended to express with her utterance: they are intentions to produce an utterance with a particular content and force. Perlocutionary intentions, on the other hand, are important for understanding why a speaker attempts to

\footnotetext{
13 'Uptake' is Austin's terminology. Uptake involves understanding the force and the content of an utterance.

${ }^{14}$ It is a controversial issue whether uptake is required for the success of an illocutionary act (E.g., Bird 2002, Langton 1993).
} 
communicate in the first place. Consider, for example, that a speaker may have the illocutionary intention to request that you $\varphi$; but it is unlikely that this is her sole reason for attempting to communicate - nor would it provide a very illuminating explanation for her utterance. If I ask you to pass me the salt, I don't ask you to do this (merely) because I want to ask you to pass me the salt; rather, I ask you this because I want you to pass me the salt. My intention to ask you to pass me the salt is my illocutionary intention; the intended perlocutionary effect, however, is that you actually pass me the salt. This picture of communication and its role in securing effects beyond the communicative exchange itself is broadly similar to Herbert Clark's (1996) account, according to which communication is itself a form of joint action that is performed in service of further joint projects. ${ }^{15,16}$ Clark writes, for example:

Signals aren't important merely because they mean things. They are important because they are used in discourse to accomplish the participants' goals. When the server in the drugstore said "I'll be right there," she meant that she would be ready to serve me soon. But she was using the signal to coordinate her and my actions at that point in our transaction. Viewed in isolation, a signal is an act by which a speaker means something. Viewed within joint activities, it is an act by which the participants coordinate the next step in their ongoing activity. Signals are coordination devices. (1996: 132)

I doubt that many would deny that perlocutionary intentions are relevant to explaining why speakers attempt to communicate; however, existing accounts of communicative success often overlook perlocutionary intentions of the kind I am interested in here. ${ }^{17} \mathrm{I}$ will argue that this kind intention is important to determining the standards for communicative success. It is, in part, because these perlocutionary intentions vary from context to context that the standards for success are contextdependent.

What are the standards for success that change with context? I will argue that it is the manner in which the hearer must inferentially understand the content expressed by the speaker that is affected: different perlocutionary intentions can make different demands on the hearer with respect to how she must

\footnotetext{
${ }^{15}$ Some aspects of my account might be in tension with Clark's picture of communication. For example, I claim that the speaker's perlocutionary intentions are central to determining the standards for communicative success; Clark (1996: 212), in contrast, emphasises how the aims of a communicative exchange are jointly developed and amended by the speaker and hearer throughout the course of a conversation. I think a version of my account could be made compatible with Clark's approach, but it is beyond the scope of this paper to explore this issue. ${ }^{16}$ Tomasello (2008) also provides a thorough development of the conception of communication as central to the coordination of cooperative projects.

${ }^{17}$ When authors do consider perlocutionary intentions in relation to communicative success, it is usually to discuss whether communicative intentions include perlocutionary intentions of the sort present in Grice's (1957) account. This issue is discussed in, e.g., Recanati (1986) and Bach (1987). The perlocutionary intentions that I appeal to in my account are not communicative intentions in this sense; rather, they are intentions that aim at effects beyond the exchange itself. Moreover, I do not claim that communicative success requires their satisfaction.
} 
understand the content that the speaker expressed. ${ }^{18}$ Note here that, although perlocutionary intentions often aim at the hearer performing some action, my claim is not that success requires the performing of an action (such as passing the salt, or forming a belief). Success is not a matter of satisfying the speaker's perlocutionary intention (of producing the desired effect); rather, success is a matter of the hearer understanding the content recovered in a way that is determined by the speaker's perlocutionary intention: the kind of understanding required is the understanding necessary for the hearer to deliberately produce the intended effect as a result of the exchange (where she might achieve such understanding without then going on to produce this effect for various reasons). As such, my position is a kind of understanding condition on communicative success: it is a context-dependent version of the understanding requirements that were introduced in Sect. 3.2. ${ }^{19}$ How this is supposed to work will become clearer through consideration of examples.

In what follows, I will present three pairs of examples. In each pair, the first example will be an instance of communication failure and the second will be an instance of communicative success. At this stage, my claim is that these are the verdicts that intuition supports. I will have a bit more to say in justification of these intuitions in Sect. 5. Across each pair, the speaker will express the same thought content and produce an utterance with the same content; the hearer will grasp the same content each time. What does change across each pair are features of the context (broadly construed): there are changes in the projects that the interlocutors are engaged in. This includes changes to the perlocutionary intentions of the speaker and also the interlocutor' background beliefs. My thesis is that the differences in communicative success should be explained by appeal to these differences in context: these features of context place different demands on the hearer with respect to the manner in which she must understand the content expressed by the speaker.

\section{Example 1a}

Sally and Hannah are at a party. Sally has noticed that Bill, who claims to be vegetarian, is eating shellfish. She utters (1) to Hannah with the perlocutionary intention that Hannah form the belief that Bill is eating shellfish.

1) [Gesturing] He is eating shellfish.

\footnotetext{
${ }^{18}$ In framing things this way, I do not mean to suggest that communication failure is always or usually solely attributable to a hearer's failure to live up to these demands - the speaker is also responsible for choosing demands that are reasonable.

${ }^{19}$ I think the correct version of the theory is a graded version according to which communication succeeds to the degree that the hearer achieves understanding along the dimensions determined by the speaker's perlocutionary intentions. I will ignore this complication in what follows.
} 
Hannah knows what shellfish are; however, her view is obstructed and so she cannot tell who Sally is gesturing at.

In this example, Hannah is unable to grasp the content that Sally expressed with her utterance (although she does recover part of it); nor can she fully understand what Sally has said to her. An invariantist will treat this as a straightforward case in which communication fails because the hearer cannot recover the object referred to by the pronoun ' $\mathrm{He}$ '. ${ }^{20}$ And, indeed, it looks initially plausible to think that the moral to draw here is simply the unsurprising one that some kinds of communication require preservation of reference. ${ }^{21}$ However, I think that this need not be the case. Consider the next example.

\section{Example $1 b$}

Sally and Hannah are at a party. Sally knows that Hannah is severely allergic to shellfish. She utters (1) to Hannah with the intention that Hannah take steps to avoid getting sick (e.g., by leaving the room).

1) [Gesturing] He is eating shellfish.

Hannah knows what shellfish are; however, her view is obstructed and so she cannot tell who Sally is gesturing at.

Once again, Hannah is unable to fully recover the content that Sally expressed. However, in this case, I think we should say that communication can succeed at least relative to Sally's perlocutionary intention. Just like in (1a), nothing enables Hannah to identify the correct referent; however, in this example it doesn't matter. Because Sally's intention is different in this case, Hannah doesn't need to know who she is gesturing at in order for communication to succeed. All that Hannah needs to understand is that someone is eating shellfish (or perhaps even just that there is shellfish present) - this much will allow her to recognise that she is in harm's way - and she can understand this without grasping the referent of 'He' in Sally's utterance. This suggests that, for at least some communicative purposes, it isn't always required that we get the reference right. Communicative success in example

\footnotetext{
${ }^{20}$ For the 'graded' conditions on communicative success, this would be better described as a case in which communication is poor. The same thing goes for the other example pairs.

${ }^{21}$ There is a debate concerning the conditions on successful de re communication (e.g., Bezuidenhout 1997, Recanati 1993, Buchanan 2014). However, much of this debate focuses on the question of whether utterance content includes modes of presentation of the referents of referring expressions. As my focus here is on inferential understanding of thought content, my argument is somewhat orthogonal to this debate.
} 
(1a) does require identification of the referent; but success in (1b) is not so demanding. The degree of understanding required appears to be constrained by the speaker's perlocutionary intention in each case. $^{22}$

\section{Example 2a}

Stanley and Hank are at the zoo to take pictures for Hank's school project on flightless birds. Approaching a pen, Stanley utters (2):

2) There is a cassowary in the pen.

Stanley utters (2) with the perlocutionary intention that Hank believe that there is a flightless bird in the pen that he might include in his project. However, although Hank understands most of the utterance, he does not fully understand the term 'cassowary'. He knows only that a cassowary is a dangerous animal.

Recall that we are assuming in these examples that Stanley and Hank share a sociolect. As such, it is reasonable to stipulate that Hank grasps the correct content. ${ }^{23}$ We can also stipulate that Hank does not work out from the context of the exchange that (Stanley believes that) a cassowary is a flightless bird (although hearers often do repair exchanges in this way). Rather, this is an example in which Hank grasps the right content but does not understand it fully. In this example, I think we should say that communication fails (or is poor), again, at least relative to Stanley's perlocutionary intention. At most, Hank's understanding would allow him to infer that there is a dangerous animal in the pen - and this is not what Stanley intended that he do. As with example (1a), it might initially look like the problem here is simply that Hank doesn't understand Stanley's utterance well enough - the invariantist might say that his understanding of 'cassowary' is not sufficient for communicative success (even if it is sufficient for grasp of content). However, consider the following.

\section{Example $2 b$}

\footnotetext{
${ }^{22}$ One worry that one might have with this example pair is that the speaker's utterance plausibly has a different illocutionary force in each case - in $1 \mathrm{~b}$, but not $1 \mathrm{a}$, the utterance is a warning. I think that a mere difference in force would not be enough to account for the difference in communicative success in these examples (e.g., the mere fact that an utterance is a warning does not obviously lessen the need to understand it). In case the reader is still concerned, the $2^{\text {nd }}$ and $3^{\text {rd }}$ example pairs do not contain this distracting feature.

${ }^{23}$ Sociolectical theories can claim that there is more to recovering content than grasping the concepts expressed by the terms apparent from an utterance's surface form (and the manner in which they are combined). Subjects may also need to grasp the explicature of an utterance, for example.
} 
Stanley and Hank are at the zoo to take pictures for Hank's school project on dangerous animals. Approaching a pen, Stanley utters (2):

2) There is a cassowary in the pen.

Stanley utters (2) with the intention that Hank believe that there is a dangerous animal in the pen that he might include in his project. Hank understands most of the utterance. He does not fully understand what 'cassowary' means; but he does know that a cassowary is a dangerous animal.

In this case, I think we should say that communication has succeeded. The illocutionary act is the same as it was in (2a); and Hank's understanding is also no different - all that has changed is Stanley's perlocutionary intention and the interlocutors' background beliefs about the project they are engaged in. ${ }^{24}$ But, intuitively, this places different demands on Hank: all Hank need understand is that there is a dangerous animal in the pen for communication to succeed relative to Stanley's intention. In this example pair, unlike the first, neither exchange requires a greater degree of understanding from Hank than the other; rather, it is the requirements on the dimensions of Hank's inferential understanding that are different. In (2a) Hank's understanding must be such that he believes that a cassowary is a flightless bird; in (2b) his understanding must be such that he believes that a cassowary is a dangerous animal.

\section{Example $3 a$}

Sigfrid and Helene are planning an itinerary for their holiday in Poland. Helene has earlier expressed an interest in visiting sites relating to Polish music history. Sigfrid utters (3) to Helene with the perlocutionary intention that Helene believe that there's a statue of a famous Polish musician in Warsaw so that she might add this to the itinerary.

3) There's a statue of Paderewski in Warsaw.

\footnotetext{
${ }^{24}$ One might object that the change in background beliefs of the hearer affects her understanding of the content she recovers (one might think this if one was a holist about inferential understanding, for example). Thus, there has been a change in understanding across the example pairs. Fortunately, I think this interpretation of the examples is consistent with my account: the kind of understanding required for success is still different across the two examples (despite no change in the thought content expressed). And, moreover, the kind of understanding required appears to track the perlocutionary intentions of the speaker: it is not the case that the hearer simply needs better understanding for communication to succeed - she needs to understand the content along different dimensions depending on the speaker's perlocutionary intentions. The speaker's perlocutionary intentions may also determine which background beliefs the hearer must have regarding the project they are engaged in.
} 
Helene understands Sigfrid's utterance quite well. However, although she knows a lot about Paderewski's political career, she is unaware that he was also a musician.

In this example, as in (2a), it is reasonable to stipulate that Helene recovers the right content. Also, once again, it is important to stipulate that this is not a case in which the hearer infers new information about Paderewski from the exchange. We can imagine that Helene is just unsure as to why Sigfrid is giving her this information. In this example, then, Helene grasps the correct content, and she even (inferentially) understands it rather well - knowing as she does that Paderewski was a Polish politician. Nonetheless, relative to Sigfrid's intention, communication fails. Now compare this with (3b).

\section{Example $3 b$}

Sigfrid and Helene are planning an itinerary for their holiday in Poland. Helene has earlier expressed an interest in visiting sites relating to Polish political history. Sigfrid utters (3) to Helene with the intention that Helene form the belief that there is a statue of a famous Polish politician in Warsaw so that she might add this to the itinerary.

3) There's a statue of Paderewski in Warsaw.

Helene understands Sigfrid's utterance quite well and knows that Paderewski was a famous Polish politician.

In this example, I think we should say that communication has succeeded. As with the previous two examples, Helene's understanding of (3) is no different than it was in (3a). However, Sigfrid's perlocutionary intention (as well as the interlocutors' background beliefs about the project they are engaged in) has changed and, intuitively, this places different demands on Helene. As with the previous example pair, neither exchange requires more understanding from Helene than the other; rather, the dimensions along which Helene must understand the content expressed by the speaker are simply different.

What these pairs of examples aim to show is that there is at least a kind of communication that is not captured on an invariantist approach. The examples motivate the claim that, for some cases, communicative success is context-dependent in the following way: holding fixed the thought content expressed by the speaker, the standards for successful communication can vary with features of the broad context of the speech exchange. Specifically, these features are the perlocutionary intentions of the speaker, in concert with the interlocutors' background beliefs about the purpose of the exchange. 
Both how well and in what respects the hearer needs to understand the speaker's utterance depends on these features of context. ${ }^{25}$ Communication succeeds when (or to the degree that) the hearer's understanding is correct along the dimensions relevant to the speaker's perlocutionary intentions in relation to the project in which the interlocutors are engaged. ${ }^{26}$ Having motivated this context-dependent approach, I will now go on to consider how an objector might reinterpret the examples that I have given in support of it.

\section{$5 \quad$ Communicative success and intuitions}

In each example pair, I claim, the first example is a case of communication failure and the second is a case of communicative success. In my presentation of examples, I was relying on intuitive judgments. Is there anything more that can be said to persuade someone who simply lacks these intuitions? When it comes to communicative success, it is difficult to say too much in support of an adjudication of success or failure without begging the question in favour of one's preferred theory. For example, it would not be convincing to merely insist that communication succeeds, in example $2 \mathrm{~b}$ (but not $2 \mathrm{a}$ ) because Hank possesses the dimensions of understanding determined to be necessary by Stanley's perlocutionary intention - that is no more than a statement of the theory that I am trying to motivate. This cuts both ways, however. It would also not be enough to claim that communication succeeds (in both $2 \mathrm{a}$ and $2 \mathrm{~b}$ ) because Hank grasps the correct content (or knowingly grasps it, etc.). Fortunately, I think that there is a little more that can be said in favour of the context-dependent approach. The intuitions that I am relying on will, I think, be reflected in the practices of language users in general (and this should be treated as a mark in favour of the approach).

In our day-to-day interactions, we frequently take ourselves to have uncovered misunderstandings. That is, we have an informal practice of judging whether exchanges have been successful. Pagin (2008) describes this practice as follows:

\footnotetext{
25 This approach is similar to that argued for in Bezuidenhout (1997). Bezuidenhout's primary aim in that paper is to argue that the communication of de re thoughts does not require shared content. She argues for a similar content account. However, in the course of arguing for the position, she suggests a context-dependent version of it. Her account is different from mine in that she thinks that preservation of reference is required for success, and she does not appeal to perlocutionary intentions.

${ }^{26}$ One might object that this account is simply a different kind of invariantism: one that requires that the hearer grasp the speaker's perlocutionary intention. However, I think this claim would be an addition to the account I am offering here rather than an alternative. I do not claim that the hearer must represent the speaker's perlocutionary intention (nor even her illocutionary intention). My claim is that success requires only that the hearer understand the content she recovers in a particular way. If we add to the account that she must also grasp the speaker's perlocutionary intention, it will still be true that success requires that her understanding of the illocutionary content expressed by the speaker is different in different contexts. This response, I think, will also be relevant to those who would claim that what the hearer must grasp is an implicature (for those who think that implicatures can be entailments - e.g., Bach 2006).
} 
What we have is a common sense practice of judging communicative success or failure in vernacular terms such as 'He did not understand,' 'She misinterpreted him,' 'He got the message,' etc. As speakers of English we do have intuitions about the correctness of such utterances with respect to various scenarios, even if we have much poorer intuitions about the exact content of the judgments expressed, about the evidence that is appropriate for making them, or about the extent to which the judgments are supported by the evidence used. (Pagin 2008: 86)

Furthermore, when we do believe that a misunderstanding has occurred, there is characteristic behaviour that we engage in to correct this perceived misunderstanding. Rapaport (2003) calls this behaviour 'negotiation': it is the process by which understandings are minimised to the point at which they are judged small enough to be ignored. ${ }^{27}$ Hearers, if invested in the exchange, will say things like 'I don't understand you' or ask 'What did you mean by that?' And speakers, if cooperative, will offer more information. Pagin suggests that an approach to communicative success should offer diagnoses of success and failure that more or less coincide with the judgments of this common-sense practice. He takes this to be an adequacy criterion on a theory of communicative success; and I think, at the very least, it should be treated as a strong mark in favour of an approach. It would be strange - and in urgent need of explanation - if one's theory predicts that most human beings are usually very wrong in their judgments of communicative success and failure. ${ }^{28}$ So, how does the context-dependent account fare in this regard? Consider example (2a) again. It is likely that someone who found themselves in Hank's position would engage in the typical negotiations of a hearer who takes themselves to lack understanding. While Hank might come to form the belief that there's a cassowary in the pen, he will be confused as to why Stanley made this assertion. He might seek further clarification, asking, for example, 'Why are you telling me this?' Even if he does not voice his confusion in the moment, he may continue to wonder until he discovers the reason that Stanley said what he did. Similarly, speakers also engage in negotiations: if Stanley finds out about Hank's partial understanding in (2a) - as he might if Hank voices his confusion - he will likely explain that a cassowary is a kind of flightless bird and thus relevant to Hank's interests.

But what of Hannah in example (1b)? An objector might point out that Hannah will attempt negotiations in this case too, despite my claim that communication has succeeded here. For example, it wouldn't be surprising if Hannah were to utter 'Who are you pointing at?' in response to Sally's utterance, even when she does understand well enough to take steps to protect her health. Isn't that - by my lights - a

\footnotetext{
${ }^{27}$ Negotiating behaviours are also discussed in Clark 1996.

${ }^{28}$ Humans can make mistakes and lack information, of course. The idea is that, if provided with relevant information, a typical speaker's judgments as to success and failure of an exchange are likely to be roughly accurate.
} 
reason to think that communication has failed after all? I think that there is something to this complaint, but it is something that my account can accommodate. What is important, for my purposes, is that there is some sense in which communication succeeds in (1b). My claim is that communication succeeds relative to Sally's perlocutionary intention that Hannah avoid getting sick. However, because we are considering success relative to intentions in this way, I think I can simultaneously accommodate the thought that (depending on how we fill out the details of the example) there is some further sense in which communication fails. The reason for this is that speakers can have more than one perlocutionary intention when communicating, and this can place multiple demands on the hearer. Imagine that, in (1b), Sally has two perlocutionary intentions: that Hannah believe that Bill is eating shellfish and that Hannah avoid getting sick. If this is the case, then, according to my account, communication will have succeeded relative to one of Sally's intentions and failed relative to another. Which intentions Sally has (and thus the standards for success) will, I think, often be reflected in the interlocutors' negotiations. For example, suppose Hannah does ask 'Who are you pointing at?' There are a number of ways in which Sally could reply that would indicate one or more different perlocutionary intentions on her part:

4) It doesn't matter! Just get out of here while you still can!

5) I was pointing at Bill. Shouldn't you get out of here?

6) Bill - I thought he was a vegetarian!

What negotiations take place (and when they terminate) will depend on what the speaker was trying to do, and this is better accommodated on my context-dependent approach. My point here is not that interlocutors' negotiations will always be a perfect guide to a speaker's original intentions; as Clark (1996: 195) notes, speakers will sometimes revise their intentions as a conversation progresses. Moreover, sometimes communication failures will never be discovered. Rather, I think it is a mark in favour of my view that it can explain why a speaker might react in these different ways to confusion on the part of the hearer. An invariantist does not offer an explanation of this - or, rather, she must claim that these different reactions are not relevant to the question of whether communication has succeeded. One advantage of my proposal, then, is that it can accommodate the fact that negotiations may cease even when the content grasped by the hearer is not very well understood and, similarly, why negotiations may sometimes continue even beyond a very high degree of understanding.

In the preceding, I don't claim to have shown that the sorts of example under consideration will be widespread. How often is communicative success context-dependent in the way I am proposing? I think there is reason to think that examples like the ones above will be quite common. Returning to the earlier thought from Clark, communication (of the sort under consideration here) is a goal-directed practice that we engage in to coordinate action in cooperative projects beyond the communicative exchange itself (for example, a completing a school project, or planning a holiday). Utterances, on this approach, 
are coordination devices, instrumental in securing further goals. I think we should expect to find examples like the ones presented above whenever the same utterance (expressing the same thought content) can be used as a coordination device in different cooperative projects. Because, as we have seen, a hearer's understanding of an utterance or thought content can vary along different dimensions, utterances will very often be multi-purpose devices. That is, for each dimension along which an utterance content can be understood, there is (at least) one perlocutionary effect which, under the right circumstances, that utterance can be instrumental in securing. Successful communication is a matter of understanding the utterance content along these contextually-determined dimensions.

\section{Conclusion}

In this paper, my aim has been to motivate a context-dependent approach to communicative success. This approach treats the standards for success as context-dependent in the following sense. Holding the thought content expressed by the speaker fixed, features of context can place different demands on a hearer with respect to the manner in which she must understand the content that she recovers. I identified two features of the context that can play this role: the perlocutionary intentions of the speaker and the interlocutors' background beliefs. I don't claim that this approach captures the only kind of communication that interlocutors can engage in. Rather, my claim is that there is an important notion of communicative success that is relevant to the coordination of action (but not defined in terms of it), and this notion of communicative success cannot be accommodated on a purely invariantist theory.

\section{Acknowledgements}

I would like to thank Lewis Pollock, Bryan Pickel, and Andrew Peet for very helpful comments on previous drafts of this paper. I also thank audiences at conferences and workshops at the University of Warsaw, University of Tartu, University of Edinburgh, and Ruhr University, Bochum.

\section{Bibliography}

Austin, J.L. 1962. How to do things with words. $2^{\text {nd }}$ edition. M. Sbisà and J. O. Urmson (eds.). Oxford: Oxford University Press, 1975.

Bach, Kent. 1987. On communicative intentions: A reply to Recanati. Mind and Language, 2: 141-154.

Bach, Kent. 2006. The top 10 misconceptions about implicature. In Drawing the boundaries of meaning. Neo-Gricean studies in pragmatics and semantics in honor of Laurence R. Horn, ed. B. Birner and G. Ward., Amsterdam: John Benjamins

Bezuidenhout, Anne. 1997. The communication of de re thoughts. Noûs, 31: 197-225.

Bezuidenhout, Anne. 1998. Is verbal communication a purely preservative process. The Philosophical Review, 107: 261-288. 
Bird, Alexander. 2002. Illocutionary silencing. Pacific Philosophical Quarterly, 83: 1-15.

Buchanan, Ray. 2014. Reference, understanding, and communication. Australasian Journal of Philosophy, 92: 55-70.

Burge, Tyler. 1979. Individualism and the mental. Midwest Studies in Philosophy, 4: 73-121.

Burge, Tyler. 1993. Content preservation. The Philosophical Review, 102: 457-488.

Cappelen, Herman. and Lepore, Ernest. 2005. Insensitive semantics. Oxford: Blackwell.

Cappelen, Herman. and Lepore, Ernest. 2007. Relevance theory and shared content. In Advances in Pragmatics, ed. N. Burton-Roberts. Basingstoke: Palgrave Macmillian.

Carston, Robyn. 2001. Explicature and semantics. In Semantics: A reader, ed. S. Davis \& B. Gillon. Oxford: Oxford University Press.

Clark, Herbert. 1996. Using Language. Cambridge: Cambridge University Press.

Davidson, Donald. 1986. A nice derangement of epitaphs. In Truth and interpretation: Perspectives on the philosophy of Donald Davidson, ed. E. LePore. Oxford: Blackwell.

Dummett, Michael. 1978. Frege's distinction between sense and reference. In Truth and other enigmas, London: Duckworth.

Evans, Gareth. 1982. The varieties of reference. John McDowell (ed.), Oxford: Clarendon Press.

Fodor, Jerry. 1994. The elm and the expert. Cambridge, MA: The MIT Press.

Fricker, Elizabeth. 2006. Testimony and epistemic autonomy. In The epistemology of testimony, ed. J. Lackey and E. Sosa. Oxford: Oxford University Press.

Goldberg, Sanford. 2007. Anti-individualism: Mind and language, knowledge and justification. Cambridge: Cambridge University Press.

Grice, H.P. 1957. Meaning. The Philosophical Review, 66: 377-388.

Jorgensen, Andrew. 2009. Holism, communication, and the emergence of public meaning: Lessons from an economic analogy. Philosophia, 37: 133-147.

Langton, Rae. 1993. Speech acts and unspeakable acts. Philosophy and Public Affairs, 22: 293-330.

Longworth, Guy. 2010. A plea for understanding. In New Waves in Philosophy of Language, ed. S Sawyer. Basingstoke: Palgrave Macmillan.

Longworth, Guy. 2018. Understanding what was said. Synthese, 195: 815-834.

Millikan, Ruth. 1984. Language, thought, and other biological categories. Cambridge, MA: MIT Press.

Newman, Anthony. 2005. Two grades of internalism (Pass and fail). Philosophical Studies, 122: 153169.

Pagin, Peter. 2008. What is communicative success? Canadian Journal of Philosophy, 38: 85-116.

Pollock, Joey. 2015. Social externalism and the problem of communication. Philosophical Studies, 172: 3229-3251.

Rapaport, William. 2003. What did you mean by that? Misunderstanding, negotiation, and syntactic semantics. Minds and Machines, 13: 397-427.

Recanati, François. 1986. On defining communicative intentions. Mind and Language, 1: 213-242. 
Recanati, François. 1993. Direct reference. Oxford: Blackwell.

Sperber, Dan. and Wilson, Deirdre. 1986. Relevance Communication and cognition. Oxford: Blackwell.

Stalnaker, Robert. 2002. Common ground. Linguistics and Philosophy, 25: 701-721.

Tomasello, Michael. 2008. Origins of human communication. Cambridge, MA: MIT Press. 